\title{
Comparação dos Valores de Desgaste Abrasivo e de Microdureza de 13 Resinas Compostas Usadas em Odontologia através do Método do Disco Retificado
}

\author{
Eduardo C. Bianchi, Paulo R. de Aguiar, Manoel C. S. Alves \\ Faculdade de Engenharia de Bauru, UNESP
}

César A. de Freitas, Ana R. Rodrigues
Faculdade de Odontologia de Bauru, USP

Oscar B. de Carvalho Jr.

Faculdades Integradas de Santa Fé do Sul, SP

\begin{abstract}
Resumo: Atualmente tem-se buscado simplificar a tarefa de caracterização da vida útil de restaurações dentárias realizadas por resinas compostas através de métodos laboratoriais, que são mais rápidos e não sofrem influência de variáveis pessoais inerentes às análises clínicas. Com este propósito, este trabalho apresenta uma nova metodologia de ensaio laboratorial para a avaliação do desgaste abrasivo de resinas compostas através do método do disco retificado. Realizaram-se ensaios de resistência ao desgaste abrasivo com 13 resinas compostas odontológicas e buscou-se analisar o comportamento da resistência ao desgaste abrasivo em relação à microdureza dessas resinas. Com a análise dos resultados concluiu-se que o método de discos retificados é eficiente para a obtenção da resistência ao desgaste abrasivo. Notou-se também ser extremamente pequeno o nível de correlação entre microdureza e desgaste abrasivo o que indica que cada resina composta tem características próprias e que o desgaste é dependente também de outros fatores.
\end{abstract}

Palavras-chave: Resinas compostas, desgaste de restaurações dentárias, resistência à abrasão, materiais dentários, dureza, in vitro.

\section{Comparing Abrasive Wear and Microhardness of 13 Dental Composite Resins}

Abstract: It is now commonplace to search for methods to assess the useful lifetime of dental restorations made of resins, which are quicker and less subjective than clinical analyses. With this purpose, this work presents a new methodology based on the grinding disk for evaluating the abrasive wear of composed resins. Resistance tests to the abrasive wear were made with 13 composed resins used as dental material, and a comparison was done with the hardness of those resins. From the data analysis, we concluded that the method of rectified disks is efficient for obtaining the resistance to the abrasive wear. Furthermore, the correlation between hardness and abrasive wear was very small, which indicates that each composed resin has its own characteristics and that the wear also depends on other factors.

Keywords: Composite resins, dental restoration wear, dental materials, hardness, in vitro.

\section{Introdução}

As resinas compostas foram desenvolvidas com o objetivo de reparar as perdas de material dentário do ser humano por apresentarem menor desgaste, maior facilidade de manuseio e por possuírem uma grande gama de cores, possibilitando alcançar a semelhança com a coloração dos dentes humanos, tornando-se praticamente imperceptíveis após a sua aplicação.

No entanto, esses materiais não se desgastam de modo semelhante ao esmalte dentário. Os desgastes provenientes das escovações e da mastigação é uma das causas do desgas- te das resinas compostas aplicadas nas restaurações, sendo fundamental estudar este fenômeno para prever o tempo de duração destas resinas.

Vários fatores influenciam no desgaste das resinas aplicadas em restaurações. Segundo Wassell et al. ${ }^{[1]}$ e Matsumura e Leinfelder ${ }^{[2]} \mathrm{o}$ desgaste dos materiais restauradores é um fenômeno complexo que envolve componentes abrasivos, adesivos, de fadiga mecânica, corrosão. A deterioração das restaurações também é influenciada pelas características e propriedades da própria resina como diferença entre os módulos de elasticidade da matriz e da carga e pelas propriedades do ambiente.

Autor para correspondência: Eduardo C. Bianchi, Depto de Engenharia Mecânica, Faculdade de Engenharia, UNESP, CP 473, CEP 17033-360, Bauru, SP, Brasil.E-mail: bianchi@feb.unesp.br 
Suzuki e Leinfelder ${ }^{[3]}$ afirmam que a resistência ao desgaste pode ser afetada sensivelmente pelo tamanho, dureza e distribuição das partículas de reforço da resina composta.

Segundo Wang et al. ${ }^{[4]} \mathrm{o}$ desgaste em resinas compostas pode ser explicado em termos do espaçamento entre partículas, arrancamento das mesmas e fratura frágil dos materiais.

$\mathrm{O}$ desgaste abrasivo das resinas compostas convencionais é caracterizado pela esfoliação das partículas de material inorgânico expostos causado pela ação abrasiva do alimento e pela tensão que a matriz da resina é submetida causando seu contínuo desgaste.

A análise do desgaste de resinas compostas aplicadas em restaurações é realizada por dois métodos distintos: o clínico (in vivo) e o laboratorial (in vitro). O método clínico consiste em se realizar restaurações em um determinado número de pacientes e analisar o desgaste sofrido após um certo tempo.

Já métodos laboratoriais vêm sendo muito utilizados, pois visam a busca de resultados mais rápidos sem interferência de variáveis ligadas aos hábitos pessoais de pacientes e apresentam maior complexidade de planejamento e de execução. Estes experimentos são realizados em laboratórios, simulando as condições bucais de desgaste que são submetidas as resinas. Apresenta maior dificuldade de comparação de seus resultados, dadas as variações metodológicas e a falta de padrões laboratoriais confiáveis ${ }^{[5]}$.

De Gee et al.$^{[5]}$ relataram com relação ao desgaste de resinas compostas, que ensaios in vitro com máquinas com total controle de variáveis oferece condições reais de determinar a resistência ao desgaste de restaurações dentárias sob condições simuladas.

Pallav et al ${ }^{[6]}$ apresentaram uma técnica in vitro de simulação do desgaste de materiais restauradores constatando-se bons níveis de correlação com os dados clínicos.

Vários pesquisadores ${ }^{[7-10]}$ vem buscando relacionar dureza e resistência ao desgaste em resinas compostas. No entanto ainda encontra-se muitas divergências quanto ao assunto.

Satou et al ${ }^{[7]}$ observaram uma correlação negativa entre a taxa de desgaste e os valores de dureza em ensaios in vitro de resinas compostas, ou seja, quanto maior a quantidade de desgaste, menor o valor de dureza. A mesma explicação foi dada Fraunhofer ${ }^{[8]}$ que afirma que resistência à abrasão está inversamente correlacionada com a dureza. Ruddel et al ${ }^{[9]} \mathrm{e}$ Momoi et al. ${ }^{[10]}$ afirmam haver uma correlação entre dureza e desgaste do material.

No entanto, Yap et al. ${ }^{[11]}$ estudaram o desgaste de materiais de restauração mostraram que não há correlação entre a dureza e a resistência ao desgaste. Harrison e Draughn ${ }^{[12]}$ também verificaram não existir um alto índice de correlação entre estes fatores afirmando que os materiais que têm altos valores de dureza não necessariamente apresentam elevada resistência ao desgaste.

A proposição deste presente trabalho baseia-se na importância que os ensaios laboratoriais (in vitro) está assumindo na análise da vida útil das resinas compostas. Também busca tratar as divergências encontradas referentes à correlação entre dureza e resistência ao desgaste destas resinas.

\section{Experimental}

\section{Materiais}

Para os ensaios foram usadas resinas compostas largamente usadas pro profissionais da área odontológica.As resinas compostas utilizadas são apresentadas a seguir juntamente com seus respectivos fabricanters: Heliomolar Ro (Vivadent); Charisma (Külzer); Durafill (Külzer); Fillmagic (Vigodent); Filtek P60 (3M Dental); Filtek Z250 (3M Dental); Helio Fill (Vigodent); Herculite (Kerr); Prodigy (Kerr); Suprafill (SSWhite); Tetric Ceram(Vivadent); TPH (Caulk/Dentsply); Filtek Z100 (3M Dental). Todas nas cores Opacas A2.

Para os ensaios de desgaste utilizou-se discos estáticos e dinâmicos com diâmetro externo de $23 \mathrm{~mm}$ e largura de $3 \mathrm{~mm}$. Os discos dinâmicos apresentavam um núcleo metálico com diâmetro de $17 \mathrm{~mm}$ uma espessura de $3 \mathrm{~mm}$ de resina composta depositada revestindo o metal.

Para a avaliação da dureza utilizou-se um dispositivo metálico de latão que apresentava uma cavidade cilíndrica cujas dimensões eram $2 \mathrm{~mm}$ de profundidade por $7 \mathrm{~mm}$ de diâmetro (Figura 1).

A resina composta foi depositada na cavidade circular do dispositivo metálico, onde foi pressionada com uma carga de $16 \mathrm{~N}$ com uma fita de poliéster colocada sob uma lâmina plana de vidro para tornar plana a superfície da resina.

Através da lâmina e da fita, a fotopolimerização era efetuada, inicialmente durante 20 segundos. A lâmina de vidro era então removida e, através da fita de poliéster, efetuava-se fotopolimerização por mais 60 segundos.

Após essas duas fases de fotopolimerização, o espécime era imediatamente submetido à medição da dureza, através de um ensaio Rockwell 30T ( HR30T) com carga de $30 \mathrm{kgf} \mathrm{e}$

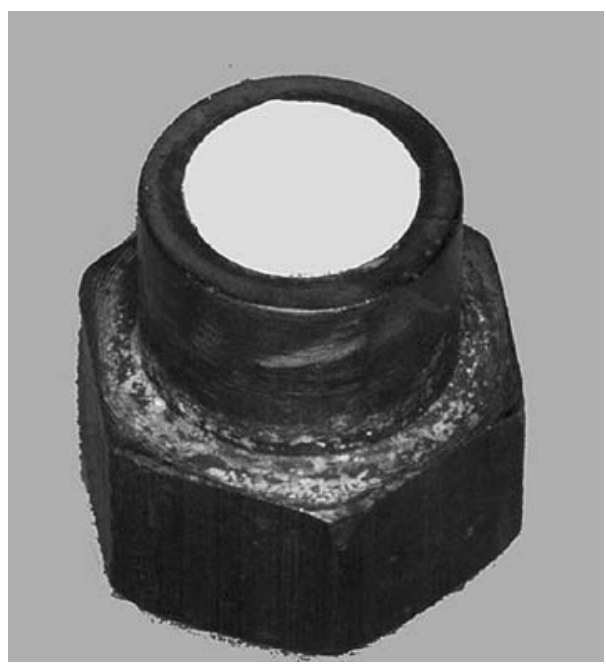

Figura 1. Dispositivo metálico para avaliação da dureza. 
aplicando-se uma pré-carga de $3 \mathrm{kgf}$ para padronizar as condições de ensaio.

Para cada resina composta foram elaborados 3 espécimes nos quais foram realizados os ensaios cuja média aritmética era considerada como valor da dureza daquele espécime.

Após realizado o ensaio de dureza, os espécimes ficavam imersos em água desionizada, por 168 horas, na temperatura de $37{ }^{\circ} \mathrm{C}$. Após ficarem imersos o ensaio de dureza era repetido.

\section{Métodos}

Como método para análise da resistência ao desgaste de resinas compostas este trabalho utilizou um novo método in vitro baseado no princípio do disco retificado desenvolvido por Coelho ${ }^{[13]}$ até então não utilizado para desgaste de resinas.

Coelho ${ }^{[13]}$ estudou os efeitos da dressagem de rebolos em operações de retificação de precisão e desenvolveu um método que consiste em manter um disco estático (confeccionado com o material da peça a ser retificada) imobilizado na extremidade de uma balança e pressionado, devido à ação de uma força normal constante, contra a superfície de um rebolo em rotação. Com o rebolo girando por um tempo determinado, verifica-se o desgaste do disco estático. O deslocamento resultante sofrido pelo disco estático em direção ao rebolo é continuamente registrado para permitir a realização dos cálculos, os quais, ao final, fornecem o valor da agressividade do rebolo.

Bianchi et al. ${ }^{[14]}$ modificaram o método do disco retificado de Coelho ${ }^{[13]}$, adaptando-o para a avaliação de materiais restauradores odontológicos. As modificações introduzidas, basicamente consistiram na substituição dos discos agressor e agredido (respectivamente, rebolo e material da peça a ser retificada) por discos metálicos revestidos de um mesmo material restaurador odontológico. O disco agressor passou a girar preso ao eixo-árvore de um cabeçote de testes e os diâmetros dos discos passaram a ser iguais.

Através deste novo método adaptado para avaliação de desgaste de resinas compostas, este trabalho buscou analisar a eficácia deste método para a análise de desgastes de resinas. Também buscou estudar o comportamento do desgaste abrasivo (agressividade) em relação à microdureza de resinas compostas usadas em restaurações dentárias.

$\mathrm{O}$ método utilizado para a avaliação do desgaste de resinas compostas baseou-se no estudo da agressividade da superfície de restaurações dentárias confeccionadas com essas resinas. Para a determinação desse fator, foi reproduzido e adaptado o método do disco retificado desenvolvido por Coelho ${ }^{[13]}$

Este método adaptado utiliza um banco de ensaios (Figura 2) acoplado a um cabeçote de testes que possui um eixo para fixação de um disco agressor, o qual gira com uma rotação pré-estabelecida proporcionada por um motor elétrico.
O conjunto banco de ensaios/cabeçote de testes (Figura 3), encontra-se posicionado sobre a mesa de uma retificadora tangencial plana, necessária à uniformização do disco agressor dinâmico.

Seu funcionamento consiste em manter posicionado um disco fixo, sem rotação, revestido em toda a sua superfície externa com a resina composta que se deseja analisar, em contato contra um disco dinâmico. O revestimento é formado pela polimerização de pequenos incrementos de resina depositados nessa região até que se recubra toda a área.

Após a regularização da superfície da resina, realizado com um rebolo convencional de óxido de alumínio, o disco fixo é pressionado contra a superfície do dinâmico, confeccionado com porcelana e retificado com um rebolo dia-

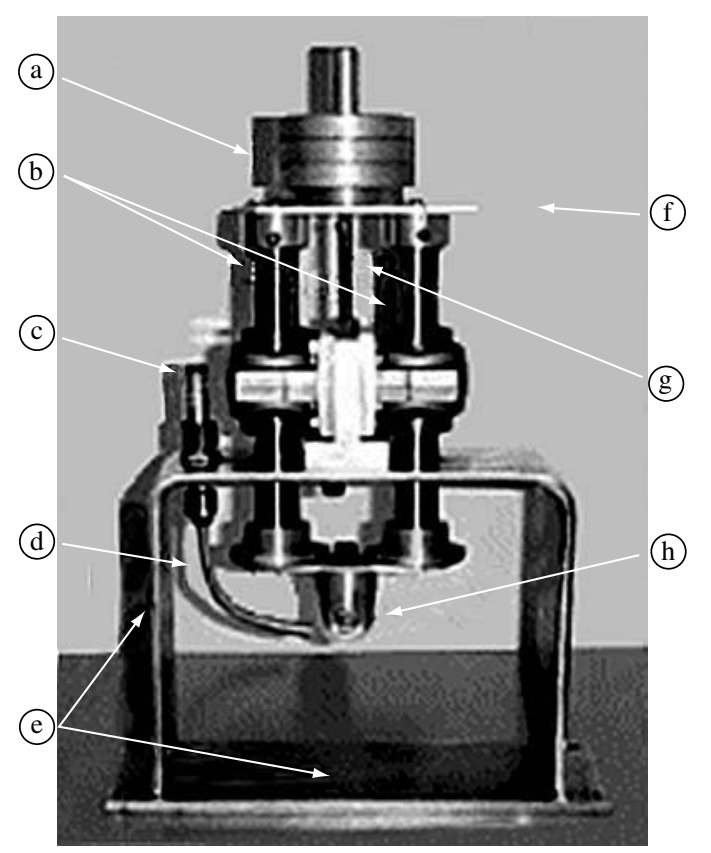

Figura 2. Banco de ensaios. a) carga aplicada; b) hastes de deslocamento vertical; c) conexão para mangueira de refrigeração por água; d) mangueira direcional do fluxo de água ao contato entre os discos estáticos e dinâmico; e) suporte com base para apoio e fixação do dispositivo no cabeçote de testes; f) apoio para contato da esfera do apalpador eletrônico; g) dispositivo de parada; e h) suporte com parafuso de fixação dos discos estáticos.

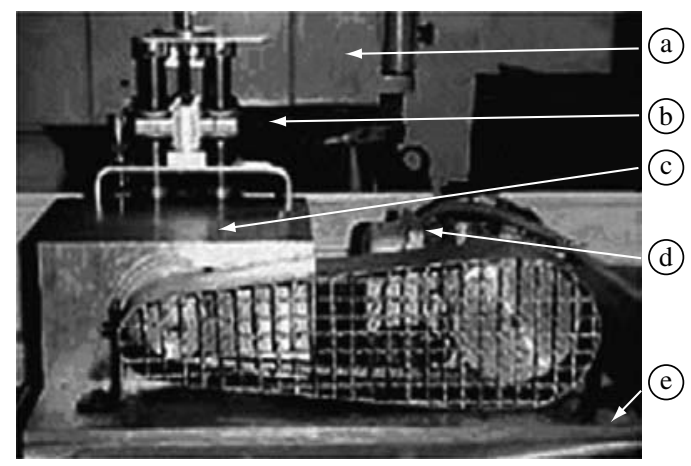

Figura 3. Banco de ensaios/cabeçote de testes. a) estrutura da máquina retificadora; b) banco de ensaios; c) estrutura do cabeçote de testes; d) motor elétrico de acionamento do cabeçote de testes; e e) base de apoio do cabeçote de testes sobre a mesa da retificadora plana. 
mantado, sob uma força normal constante de $16 \mathrm{~N}$ conforme Figura 4.

O deslocamento do disco fixo contra o disco dinâmico $(\delta)$, à medida que ocorre o desgaste da resina, é registrado em função do tempo por meio de um medidor eletrônico de deslocamento conectado a uma placa de aquisição em um computador.

O desgaste da resina provoca o deslocamento do dispositivo, o qual é registrado em forma de sinais de tensão elétrica que são enviados à placa que, a partir de uma equação de calibração previamente implementada, calcula o respectivo deslocamento real do dispositivo, gerando um gráfico como o apresentado na Figura 5.

A parte curva do gráfico apresenta o desgaste real das resinas e é esta parte do gráfico utilizada para o cálculo da agressividade.

Conforme a metodologia proposta por Coelho ${ }^{[13]}$, eleva-se o tempo de ensaio a 2/3 para se obter a tangente da curva de deslocamento do dispositivo (Figura 6), cujo coeficiente angular é utilizado na equação 1 juntamente com os parâmetros utilizados nos ensaios (largura do disco estático $(b=3 \mathrm{~mm})$, raio do disco estático para o respectivo ensaio (r) e força normal aplicada $\left(\mathrm{F}_{\mathrm{n}}=16 \mathrm{~N}\right)$ ), para o cálculo da agressividade $(\mathrm{k})$ da resina em questão.

$$
k=\frac{2 b \sqrt{4 r}}{3 F_{n}}\left(a_{1}\right)^{2 / 3}
$$

onde, $k\left(\mathrm{~mm}^{3} / \mathrm{N} . \mathrm{s}\right)$ é a agressividade da resina; $F_{n}(\mathrm{~N})$ a força normal necessária à remoção de material; $b(\mathrm{~mm})$ a largura dos discos fixos; $r(\mathrm{~mm})$ o raio dos discos e $a_{1}$ o coeficiente angular da reta de regressão linear.
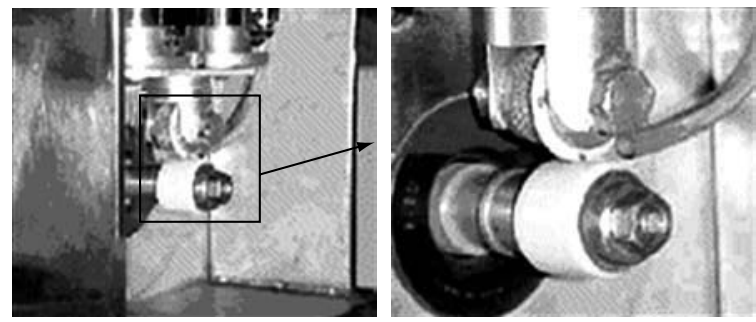

Figura 4. Posicionamento do disco no conjunto banco de ensaios/cabeçote de testes.

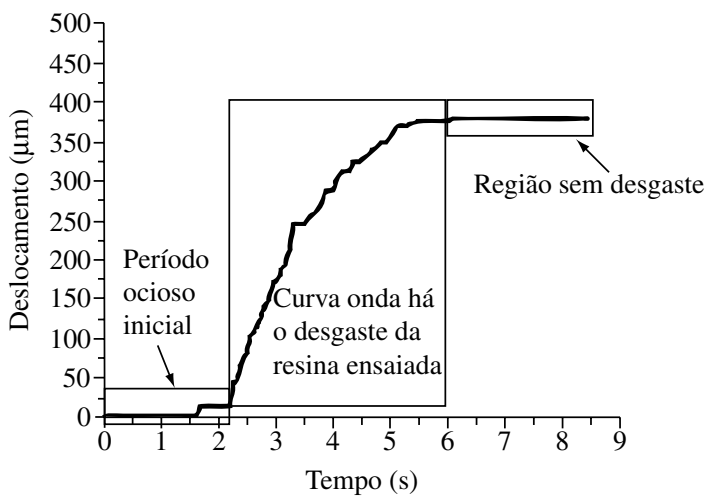

Figura 5. Gráfico típico de deslocamento do dispositivo em função do tempo, obtido nos ensaios de agressividade das resinas compostas.
Assim, partindo-se da premissa que os autores se divergem quanto à possível correlação existente entre as duas propriedades dos materiais verificou-se a necessidade de comprovar qual das hipóteses seria a mais adequada para as resinas em questão.

\section{Resultados e Discussão}

A Figura 7 mostra exclusivamente a classificação por ordem de microdurezas das 13 resinas ensaiadas. O gráfico da Figura 8 apresenta a classificação destas mesmas resinas em relação aos seus valores de agressividade.

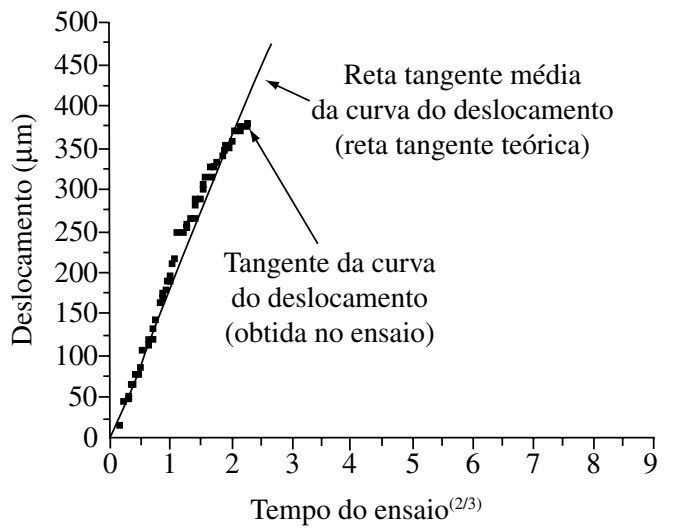

Figura 6. Gráfico mostrando a tangente da curva de desgaste das resinas, cujo valor do coeficiente angular é utilizado no cálculo da respectiva agressividade.

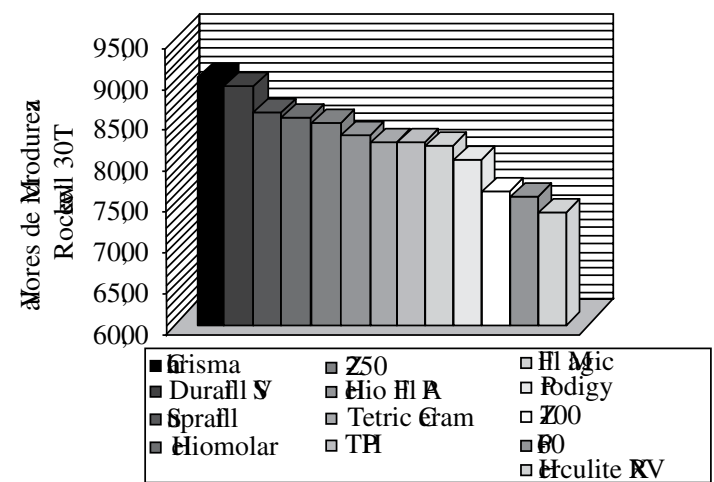

Figura 7. Gráfico com a classificação das 13 resinas segundo suas microdurezas, apos 168 horas.

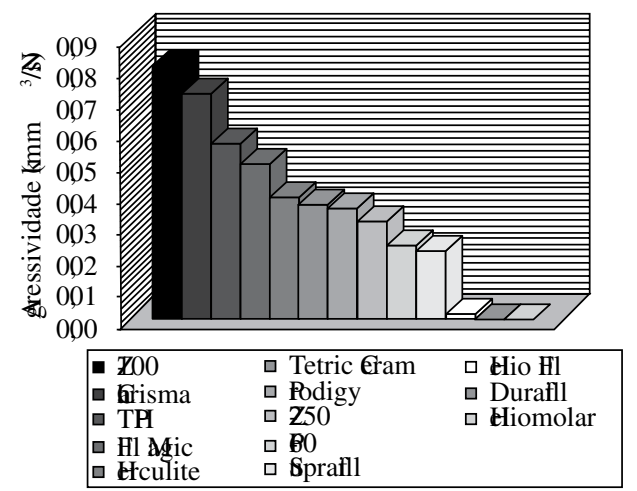

Figura 8. Gráfico com a classificação final das 13 resinas compostas ensaiadas em função dos valores médios de agressividade. 
Os resultados obtidos nos ensaios de agressividade das resinas são apresentados na Tabela 1. A partir desses resultados, para a comparação dos tipos de resina quanto à agressividade, utilizou-se a técnica estatística da análise de variância seguida do teste de Tukey (5\%), de acordo com Costa Neto ${ }^{[15]}$ a fim de verificar possíveis semelhanças e/ou diferenças significativas entre as resinas ensaiadas.

A Tabela 2 mostra as 13 resinas agrupadas por semelhanças entre seus valores médios de agressividade. Assim, na referida tabela, letras iguais significam desgastes semelhantes, indicando um comportamento similar quanto ao desgaste.

A análise da Tabela 2 indica que os mecanismos de desgaste da maior parte das resinas são semelhantes, ou seja, há vários grupos com um número razoável de resinas, evidenciando que não há diferenças significativas entre suas agressividades. É o caso, por exemplo, do grupo formado por: Filtek Z250, Prodigy, Tetric Ceram e Herculite, dentre outros.

Como a agressividade é inversamente proporcional à resistência ao desgaste abrasivo das resinas, ou seja, aque- la com maior agressividade é a que sofreu maior desgaste, sendo, portanto a menos resistente, de acordo com a Figura 8, apresenta-se a classificação decrescente (da mais resistente para a menos resistente) das resinas, segundo o critério de resistência mecânica: Heliomolar Ro, Durafill e Filtek A110 (todas como sendo as mais resistentes. Para estas não se obteve deslocamento, então não é possível distinguir resistência entre elas); Helio Fill; Point 4; Flow It; Natural Flow; Suprafill; Filtek P60; Filtek Z250; Tetric Flow; Revolution; Prodigy; Tetric Ceram; Herculite; Fillmagic; Tph; Charisma; Z100.

Deve-se observar que os valores numéricos de agressividades obtidos para as resinas são pertinentes à metodologia e parâmetros de ensaio utilizados, servindo-se então apenas como índices comparativos para a classificação delas.

Para interpretar tais resultados, uma análise estatística foi realizada de forma a verificar o coeficiente de correlação existente entre tais valores e detectar seu comportamento real. Para isso, os valores de microdureza e agressividade das

Tabela 1. Resultados obtidos nos ensaios de agressividade das resinas.

\begin{tabular}{lccc}
\hline Resinas ensaiadas & Agressividade média $\left(\mathbf{m m}^{\mathbf{3}} / \mathbf{N} . \mathbf{s}\right)$ & Desvio padrão $\left(\mathbf{m m}^{\mathbf{3}} \mathbf{\mathbf { N } . s}\right)$ & Variância $\left(\mathbf{m m}^{\mathbf{3}} \mathbf{\mathbf { N } . \mathbf { s } )}\right.$ \\
\hline Z100 & 0,08088780 & 0,0109130 & $8,9322 \mathrm{E}-05$ \\
Charisma & 0,07204334 & 0,0146340 & $1,6061 \mathrm{E}-04$ \\
TPH & 0,05636489 & 0,0051350 & $2,1096 \mathrm{E}-05$ \\
Fillmagic & 0,04958310 & 0,0036420 & $1,0613 \mathrm{E}-05$ \\
Herculite & 0,03888115 & 0,0034680 & $9,6199 \mathrm{E}-06$ \\
Tetric Ceram & 0,03743786 & 0,0030500 & $7,4407 \mathrm{E}-06$ \\
Prodigy & 0,03600442 & 0,0027290 & $5,9560 \mathrm{E}-06$ \\
Filtek Z250 & 0,03092884 & 0,0052080 & $2,1702 \mathrm{E}-05$ \\
Filtek P60 & 0,02321755 & 0,0070500 & $4,4186 \mathrm{E}-05$ \\
Suprafill & 0,02152813 & 0,0043440 & $1,6983 \mathrm{E}-05$ \\
Helio Fill & 0,00145989 & 0,0003850 & $7,4231 \mathrm{E}-08$ \\
Durafill & 0 & 0 & 0 \\
Heliomolar Ro & 0 & 0 & 0 \\
\hline
\end{tabular}

Tabela 2. Resultado do Teste de Tukey (5\%) aplicado às resinas.

\begin{tabular}{|c|c|c|c|c|c|c|c|c|c|c|c|c|c|c|c|}
\hline Resinas ensaiadas & $\begin{array}{c}\text { Agressividade média } \\
\left(\mathrm{mm}^{3} / \mathbf{N} . \mathbf{s}\right)\end{array}$ & Gr & od & esi & se & Iha & es c & re & ร̃ão & de & ist & Tes & de & кеy & $\%)$ \\
\hline Durafill & 0 & A & & & & & & & & & & & & & \\
\hline Heliomolar Ro & 0 & A & & & & & & & & & & & & & \\
\hline Helio Fill & 0,00145989 & & B & & & & & & & & & & & & \\
\hline Suprafill & 0,02152813 & & & $\mathrm{C}$ & D & & & & & & & & & & \\
\hline Filtek P60 & 0,02321755 & & & $\mathrm{C}$ & $\mathrm{D}$ & $\mathrm{E}$ & & & & & & & & & \\
\hline Filtek Z250 & 0,03092884 & & & & D & $\mathrm{E}$ & $\mathrm{F}$ & & & & & & & & \\
\hline Prodigy & 0,03600442 & & & & & & $\mathrm{~F}$ & G & $\mathrm{H}$ & I & & & & & \\
\hline Tetric Ceram & 0,03743786 & & & & & & $\mathrm{~F}$ & G & $\mathrm{H}$ & I & $\mathrm{J}$ & & & & \\
\hline Herculite & 0,03888115 & & & & & & $\mathrm{~F}$ & $\mathrm{G}$ & $\mathrm{H}$ & $\mathrm{I}$ & $\mathrm{J}$ & K & & & \\
\hline Fillmagic & 0,04958310 & & & & & & & & & & $\mathrm{~J}$ & $\mathrm{~K}$ & $\mathrm{~L}$ & M & \\
\hline $\mathrm{TPH}$ & 0,05636489 & & & & & & & & & & & & $\mathrm{~L}$ & M & \\
\hline Charisma & 0,07204334 & & & & & & & & & & & & & & $\mathrm{~N}$ \\
\hline $\mathrm{Z100}$ & 0,08088780 & & & & & & & & & & & & & & $\mathrm{~N}$ \\
\hline
\end{tabular}


13 resinas são apresentados lado a lado na Tabela 3, a qual foi utilizada na construção do gráfico de dispersão das duas propriedades apresentado na Figura 9.

Baseando-se nessa dispersão, calculou-se o coeficiente de correlação entre as duas propriedades, obtendo-se $\mathrm{r}=-0,247$, ou seja, um valor muito baixo para se dizer que há correlação entre elas (correlação existe para $r \approx 1$ ). Isso também pode ser verificado pelo gráfico, onde não nota-se uma tendência de comportamento dos valores.

Porém, o que pode ser comentado é que o coeficiente obtido tem o sinal negativo, indicando que, se houvesse correlação significante ela seria negativa, ou seja, a microdureza seria inversamente proporcional à agressividade; ou ainda: haveria uma correlação positiva entre microdureza e resistência ao desgaste abrasivo, sendo que esta última propriedade é inversamente proporcional à agressividade.

Desse modo confirma-se a teoria apresentada por Harrison $\&$ Draughn $^{[12]}$, que afirmam que o desgaste abrasivo é decorrente de vários fatores, sendo então uma propriedade que apresenta relativa complexidade para análise.

Além deste, outros autores como Pagniano \& Johnston ${ }^{[16]}$ e Suzuki et al. ${ }^{[3]}$ que constataram, através dos resultados ob-

Tabela 3. Valores de agressividade e microdureza Rockwell 30T (168 horas) das 13 resinas.

\begin{tabular}{lcl}
\hline \multicolumn{1}{c}{ Resina } & $\begin{array}{c}\text { Microdureza } \\
\text { Rockwell 30T }\end{array}$ & $\begin{array}{c}\text { Agressividade } \\
\left(\mathbf{m m}^{3} / \mathbf{N . s}\right)\end{array}$ \\
\hline Charisma & 90,23 & 0,07204334 \\
Durafill & 89,40 & 0 \\
Fill Magic & 81,96 & 0,04958310 \\
Helio Fill & 83,00 & 0,00145989 \\
Heliomolar & 85,30 & 0 \\
Herculite & 73,60 & 0,03888115 \\
P-60 & 75,70 & 0,02321755 \\
Prodigy & 80,23 & 0,03600442 \\
Suprafill & 85,90 & 0,02152813 \\
Tetric Ceram & 82,20 & 0,03743786 \\
TPH & 82,10 & 0,05636489 \\
Z-100 & 76,26 & 0,08088780 \\
Z-250 & 84,63 & 0,03092884 \\
\hline
\end{tabular}

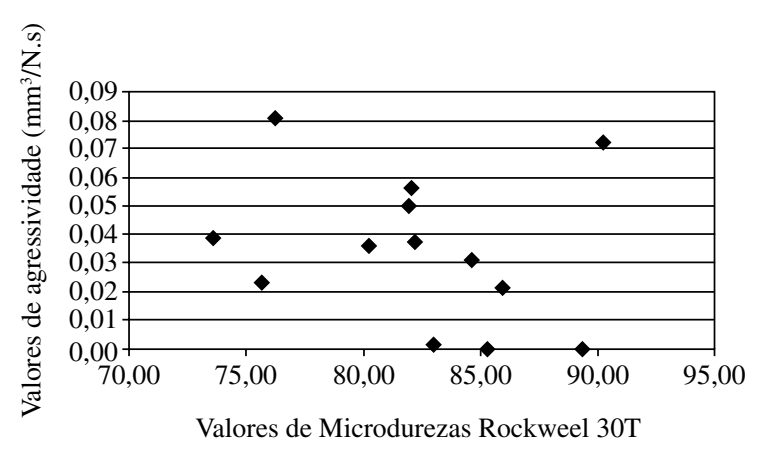

Figura 9. Gráfico de dispersão dos valores de agressividade e microdureza correlacionados. tidos em seus experimentos, não haver correlação entre as duas propriedades.

No entanto, isto contraria alguns autores como, por exemplo, Fraunhofer ${ }^{[8]}$, que relacionou a dureza com a resistência à abrasão e o desgaste, ou como Satou et al. ${ }^{[7]}$, que observaram uma correlação positiva entre resistência ao desgaste e dureza, além de Ruddel et al..$^{[9]}$, Willems et al. ${ }^{[17]}$ e Momoi et al. ${ }^{[10]}$, que afirmam haver relação entre essas duas propriedades.

\section{Conclusões}

Com base nos resultados e diante da metodologia utilizada foi possível concluir que o método de ensaio utilizado, baseado no princípio desenvolvido por Coelho ${ }^{[13]}$, mostrou-se capaz de realizar a aquisição dos dados e detectar os diversos comportamentos obtidos para cada tipo de resina avaliada, mostrando-se portanto aplicável e confiável. É um dispositivo versátil com possibilidade de controle de variáveis importantes como tempo de desgaste, profundidade de desgaste, dimensões dos discos utilizados para os ensaios com possibilidade para análise de outros materiais diferentes de resinas compostas.

A classificação obtida para as resinas ensaiadas é considerada válida para utilização por dentistas e protéticos como forma de classificar quais têm melhor comportamento quanto ao desgaste abrasivo.

Não foi detectado uma correlação entre a resistência ao desgaste abrasivo e microdureza nas resinas ensaiadas, demonstrando não ser uma tarefa possível, visto que não há uma coerência nos resultados.

Desse modo, prevalece a divergência entre conclusões a respeito da existência ou não de correlação entre microdureza e resistência ao desgaste abrasivo de resinas compostas.

\section{Agradecimentos}

Agradecimentos à FAPESP (Fundação de Amparo à Pesquisa do Estado de São Paulo) pelo apoio concedido para a realização do presente trabalho. Agradecimentos especiais aos colaboradores deste trabalho: Manoel Henrique Salgado,Carlos Elias da Silva Junior e Michele Paoline de Marins Ulhoa da Faculdade de Engenharia de Bauru (FEB) da Universidade Estadual Paulista (UNESP) Bauru SP, Ana Rita Rodrigues e Márcia Furtado Antunes de Freitas da Faculdade de Odontologia de Bauru (FOB) da Universidade de São Paulo(USP) Bauru - SP.

\section{Referências Bibliográficas}

1. Wassell, R. W.; Mccabe, J. F. \& Walls, A. W. G. - J. Dent. Res., 73, p.1546 (1994).

2. Matsumura, H.\& Leinfelder, K. F. - Quintessence Int., 25, p. 425 (1994).

3. Suzuki, S.; Leinfelder, K. F.; Kawai, K. \& Tsuchitani, Y. - Amer. J. Dent., 8, p.173 (1995). 
4. Wang, W.; Dibenedetto, A. T. \& Goldberg, A. J. - Wear, 219, p.213 (1998).

5. De Gee, A. J.; Pallav, P. \& Davidson, C. L. - J. Dent. Res., 65, p.654 (1986).

6. Pallav, P.; Davidson, C. L. \& De Gee, A. J. - J. Prosth. Dent., 59, p.426 (1988).

7. Satou, N.; Khan, A. M.; Satou, K.; Satou, J.; Shintani, H.; Wakasa, K. \& Yamaki, M. - J. Oral. Rehab., 19, p.31 (1992).

8. Fraunhofer, J. A. V. - Brit. Dent. J., 130, p.243 (1971).

9. Ruddel, D. E.; Thompson, J. Y.; Stamatiades, P. J.; Ward, J. C.; Bayne, S. C. \& Shellard, E. R. - J. Dent. Res., 78, Special issue, p.156 (1999).

10. Momoi, Y.; Yamamoto, S.; Murakami, T.; Ikejima, I.\& Kohno, A. - J. Dent. Res., 79, Special issue, p.280 (2000).

11. Yap, A. U. J.; Theo, S. H.; Hastings, G. W. \& Lo, C. S. J. Oral Rehab., 24, p.574 (1997).
12. Harrison, A. \& Draughn, R. A. - J. Prosthet. Dent., 36, p.395 (1976).

13. Coelho, R. T. - "Estudo Experimental da Profundidade de Dressagem de Rebolos na Retificação de Precisão Usando o Método do Disco Retificado”, Dissertação de Mestrado, Universidade de São Paulo, Brasil (1991).

14. Bianchi, E. C.; Dias, A. C. P.; Bianchi, A. R. R. \& Freitas, C. A. - "Avaliação do desgaste abrasivo de resinas compostas”, in: Anais do $4^{\circ}$ Congresso de Engenharia Mecânica Norte/Nordeste, p.169, Recife - PE, (1996).

15. Costa Neto, P. L. O. - "Estatística", Ed. Edgard Blücher, São Paulo, (1997).

16. Pagniano, R. P. \& Johnston, W. M. - J. Prosth. Dent., 70, p.214 (1993).

17. Willems, G.; Lambrechts, P.; Braem, M. \& Vanherle, G. - Quintessence Int., 24, p.641 (1993).

Enviado: $23 / 01 / 06$

Reenviado: $26 / 06 / 06$

Aceito: 07/12/06 